\title{
The effect of electronic human resources management on organizational health of telecommuni- cations companies in Jordan
}

\author{
Ahmad AlHamad ${ }^{\text {a }}$, Muhammad Alshurideh ${ }^{\text {b* }}$, Khaled Alomaric, Barween Al Kurdid ${ }^{\text {, Haitham }}$ \\ Alzoubi $^{\mathrm{e}}$, Salima Hamouche ${ }^{\mathrm{f}}$ and Sulieman Al-Hawary ${ }^{\mathrm{g}}$
}

${ }^{a}$ Department of Information Systems, College of Computing and Informatics, University of Sharjah, United Arab Emirates

${ }^{b}$ Department of Marketing, School of Business, The University of Jordan, Jordan

${ }^{c}$ Abu Dhabi University, United Arab Emirates

${ }^{d}$ Department of Marketing, Faculty of Economics and Administrative Sciences, The Hashemite University, Zarqa, Jordan

${ }^{e}$ School of Business, Skyline University College, United Arab Emirates

${ }^{f}$ Department of Management, College of Business Administration, University of Sharjah, United Arab Emirates

${ }^{g}$ Department of Business Administration, Faculty of economics and Administrative sciences, Al al-Bayt University, Mafraq, Jordan

\section{CH RON I C L E A B S T RACT}

Article history:

Received: July 23, 2021

Received in revised format: Sep-

tember 18, 2021

Accepted: December 18, 2021

Available online: December 20,

2021

Keywords:

Electronic human resources man-

agement

E-HRM

Organizational Health

Telecommunications companies

Jordan
This study aimed at examining the impact of E-HRM on organizational health. It focused on telecommunications companies operating in Jordan. Data were primarily gathered through self-reported questionnaires created in Google Forms and distributed to a purposive sample of senior managers via email. AMOSv24 was used to test the study hypotheses. The results of the study show that EHRM has a positive impact on organizational health. Based on the obtained results, the researchers recommend managers and decision-makers of the telecommunications companies in Jordan to invest in electronic human resources systems, which can help them fully implement human resources practices electronically, to obtain economic savings and to be able to attract talents. The study also highlights the importance of focusing more on the electronic training and development process in order to raise individuals' practical capabilities, which is reflected in their creativity.

\section{Introduction}

In light of increasing progress in modern technology use, computer applications and communication sciences, and the increasing investment in information systems that led to a massive digital revolution in business organizations functions (AlHamad \& Al Qawasmi, 2014; Alshurideh et al., 2019; Ahmad et al., 2021; Al Kurdi et al., 2021; Hamouche, 2021). Due to knowledge explosion as well as internal and external business environment changes, E-HRM use has become a basic requirement and an urgent necessity for human resources management in all services and industrial business sectors (AlHamad et al., 2021a\&b; Al-Maroof et al., 2021; Shamout et al., 2022), where the human element plays an important role in bringing positive changes that are reflected in the whole world economies, so business organizations have become aware that the key to success depends on resources effective management (Alkalha et al., 2012; Alshraideh et al., 2017; Al-Lozi et al., 2018; Alshurideh et al., 2020, Hamouche \& Chabani, 2021). Thus, the science of E-HRM emerged.

E-HRM is not a product of the hour but is the result of successive developments and great effort in traditional human resource management (HRM) practices that were limited to HRM routine tasks (such as recruitment, employment, incentives and

* Corresponding author.

E-mail address: m.alshurideh@ju.edu.jo (M. Alshurideh)

(C) 2022 by the authors; licensee Growing Science, Canada. doi: $10.5267 /$ j.ijdns.2021.12.011 
rewards, and leaves) to expand these tasks and become more strategy by automating traditional HR practices (Alshurideh et al., 2021; Asfahani, 2021). E-HRM is seen as a modern administrative approach that requires necessary, high human capabilities, change in management methods, organizational structures, and development of electronic infrastructure so that organizations can raise their services levels and employee efficiency.

Organizational health is a concept that has aroused growing interest in organizations as well as the scientific community. It is defined as an organization's ability to work efficiently and effectively, achieving a state of continuous growth and development to form an integrated system towards achieving organizational goals (Miles, 1969). It affects job satisfaction, employee effectiveness, and performance, (Zu'bi et al., 2012; Alshurideh et al., 2016; Alshurideh et al., 2019; Kurdi et al., 2020a\&b; Ghazal et al., 2021; Xenidis \& Theocharous, 2014). This concept is closely related to employees' perceptions of equity, justice, and participation within the organization. (Bottiani et al., 2014). Moreover, it can help to foster harmony between organizations, employees, and leaders which can lead to the success and the sustainability of organizations. In addition, some authors suggest that there is a strong relationship between organization vision and organizational health (Alameeri et al., 2020; Aburayya et al., 2020). Organization leaders play a crucial role in the promotion of organizational health, they are accountable for achieving the organization's goals and vision (Al-Dhuhouri et al., 2020; AlShehhi et al., 2020). In this sense, leadership styles are important sources of organizational health in organizations (Korkmaz, 2007; Odeh et al., 2021; Allozi et al., 2022). Organizational health is also achieved when employees want to work and stay in and are proud to be part of the organization.

Organizational health can be influenced by human resource management practices as well as new information technologies considering their predominant presence in most organizations nowadays, leading to the development of the concept of EHRM concept which refers to the integration of these new technologies in the human resource department. To the best of our knowledge, no study has already linked E-HRM with the concept of organizational health. This study contributes to the expansion of human resource management research by examining the impact of E-HRM practices in achieving organizational health in telecommunications companies in Jordan. It explores the advantage of integrating information technology into human resource management to enhance the organization's ability to attract the best of human resources from different environments to achieve the ideal diversity of the human element (Otair \& Hamad, 2005; Al-Mashaqbeh \& Al Hamad, 2010; AlHamad et al., 2014; AlHamad \& AlHammadi, 2018; AlHamad, 2020). Addressing organizational health enhances organizations' creative climate through the selection of creative employees appropriately, as the selection process depends on the organizational flexibility context that organizations have so that this flexibility allows to bring the required organizational change processes perfectly (Jenaabadi and Javan, 2014; AlMehrzi et al., 2020). Organizational health can also help organizations to adapt to the environment and support members' cohesion to achieve the organizational goals.

\section{Literature review and hypotheses development}

\subsection{Electronic human resources management (E-HRM)}

In today's information technology-based economy, the need for an E-HRM system has become necessary to meet human resources challenges in the twenty-first century (Zafar, 2010). The rapid increase of Internet users in the past decades has greatly contributed to bringing a significant change in business organizations and bringing significant changes in organization activities and functions, especially the human resources function. HRM in organizations today witnessed a major change as a result of information and communication technology development through the Internet and website technology use, which contributed to the increase in HRM practices enhancement (Strohmeier \& Kabst, 2009), which is called E-HRM. This term gained great importance along with the e-commerce concept in the 1990s as organizations started using the Internet and websites for a large number of HRM functions such as employee payment, employee directory, and employee communication (Gueutal \& Stone, 2005). The E-HRM is an extension of the HRM information systems, which deals with the traditional tasks and strategic tasks of HRM (Zafar et al., 2010).

The researchers emphasized that the emergence of Internet networks and communication and information technology development contributed to bringing many changes in the organization, such as reducing hierarchy and administrative levels number, authority levels, and decision-making points (Alshurideh et al., 2019; Al Kurdi et al., 2020; Alzoubi et al., 2021), so EHRM is a concept appeared as a natural response of this stage variable (Mousavidavondi, Fartas, 2012) .The electronic human resources department became able to transform human resources management into practical application to employees and managers. Thus, each of them was able to access these jobs through electronic interfaces widely through the organizations' internal network. Electronic human resource management (E-HRM) concept is a result of traditional human resource management practices development series that are limited to carrying out human resource management routine tasks (such as employees' recruitment, employment, compensation, and leaves) and then these tasks expanded to become more strategy through automating traditional HR practices. Electronic human resource management literature dealt with different E-HRM definitions, Bondarouk and Ruël (2009) defined electronic human resource management (E-HRM) as "an umbrella of the human resource management and information technology integration mechanisms which aim to create management and employee value within organizations". Fisheret (2014) considers that this process consists of steps series through which the organization seeks to attract qualified applicants using various electronic recruitment methods-HRM is defined as a wide strategy used as technical scalability and characterized by being flexible and integrated to link internal processes and knowledge workers directly to organization business objectives (Marler, 2009). Electronic Human Resource Management (EHRM) is the information technology planning and implementation and individuals of human resource functions joint 
performance support (Strohmeier, 2007). E-HRM is defined as a method of implementing HR strategies, policies, and practices in organizations through informed and directed support and/or full use of technology-based on internet channels (Challapalli, 2005). Ramayah (2011) defined E-HRM as a technology that provides human resources functions the ability to create new areas and ways that contribute to the organization's success. E-HRM is also defined as administrative support for organizations human resources functions using internet technology (Voermans \& Veldhoven, 2017), therefore, Bondarouk et al. (2009) defined E-HRM as an umbrella of all mechanisms and implications of the integration between human resource management and information technology in order to create value for employees and management in organizations. Researchers approached E-HRM practices differently. Srivastava (2017), said that e-HR practices are (e-selection, e-recruitment, e-training), Swaroop and Zafar (2012) added that the e-HR practices consist of (e-learning, e-training, e-compensation, e-leave, eprofile, e-recruitment, e-selection). After reviewing the literature of E-HRM practices that were addressed by researchers from different points of view in different organizational conditions, the researchers see that E-HRM practices consist of (electronic recruitment and selection, electronic training and development, electronic performance evaluation, electronic compensation).

Electronic recruitment and selection: Organizations use the Internet as one of external attraction and recruitment sources. The first use of the internet to practice recruitment was in the mid-nineties when the public media called it the "recruitment revolution" because it achieved the success that brought great benefits for both organization and human resource management (Dhamija, 2012). The term electronic recruitment refers to the process by which an organization posts vacancies on its websites or other recruitment sites over the internet, and then allows applicants to submit work applications or send their CV electronically (by using e-mail or any other electronic way (Galanaki, 2002).

Electronic training: The human resources management system diagnoses the skills, capabilities, and knowledge that the organization possesses in order to help prepare development and training plans for working individuals that are commensurate with the organization's needs with the possibility of redistributing them to jobs according to their skills, knowledge, and capabilities and in proportion to their academic qualifications (Al Hamad, 2016; Ahmad et al., 2020; Al Mehrez et al., 2020). Information technology has greatly supported training practices in recent years, enabling employees to obtain education and training without the need for physical places for that purpose. Organizations have also been able to enhance their competitiveness by promoting a continuous learning culture, and continuous online training. It is thus more flexible to meet the organization's current and future needs (Ramayah, Ahmad \& Hong, 2012; AlHamad et al., 2012).

Electronic performance appraisal: human resources performance appraisal can be done using the Internet, and this means that managers can submit performance appraisals information directly to the human resources department via electronic forms, and this reduces papers use for both supervisor and observer, which helps reduce time, cost and effort spent in human resources management, there are also managers self-service applications that allow them to enter performance appraisal results immediately, in addition to the possibility of setting employee performance goals and results, planning performance and publishing them on their personal pages (Piggot-Irvine, 2013). The main purpose of the performance appraisal system is to control employee performance and behavior, to ensure that his behavior is consistent with organizational goals.

Electronic Compensation Systems: The electronic compensation system includes all employees' salary records in the organization, whether they work on internal or external contracts such as consultants, as well as those working temporarily with the organization on hourly or any other system organization followed (Elshamy et al., 2017; Alomari et al., 2019; Yuliawati et al., 2021). The system also includes holidays and leave tracking, and supports employee retirement plans, health care, and other employee benefits or incentives. Electronic compensation systems are used for various purposes such as: developing and implementing a wage system, providing benefits, evaluating compensation system effectiveness. The organization can develop a compensation system by identifying job important characteristics, determining the relative compensating value using job analysis, and converting job evaluation points into the wage structure by surveying wage rates in the labor market (Candy \& Miller, 2003). According to Willis (2001), compensation is one of the important issues of attracting and retaining talent in organizations, organizations mainly assume that money influences employee behavior in shaping his attitudes, Parker \& Wright (2001), therefore, wages affect workforce attraction and retention (Parker \& Wright, 2001).

\subsection{Organizational health}

Recently, organizational health concept has become an important concept, so organizations paid attention to it, based on the fact that organizational health levels affect various concepts such as job satisfaction, effectiveness, employee performance, and achievement, and are also affected by these variables, just as the organization with organizational health is the one that implements its organizational processes efficiently (Xenidis \& Theocharous, 2014). The organizational health concept in the literature refers to a description of the organizational environment aspect related to workers. Miles (1969) defined organizational health as an organization's ability to work efficiently and effectively, achieving a state of continuous growth and development to form an integrated system towards achieving organizational goals. As Rego et al. (1992) pointed out that organizational health is a state in which the administrative and technical levels align in terms of the ability to meet the organization's needs and enhance the ability to face external threats that may affect its progress and growth. Vansant (2000) linked organizational health and job satisfaction as an actual state and contributed to it through formal and informal organizational structures to improve the organizational environment reality to enhance employees' work in the organization. Hansson (2008) also referred to organizational health as the organizational state that organizations enjoy achieving the increasing integration between 
employees' goals and the organization's goals of productivity and profitability. Organizational health concept is closely related to workers' perceptions of being caring, equity, justice, and participation levels. (Bottiani et al., 2014).

Organizational health concept also allows giving an overall image about organizations health states, where there are indications of organizations health, including committed employees, who enjoy high morale and high performance, and employees go to work with interest and are proud of working in their workplace ,organizational health is the organization's adaptation, improvement and expansion to its environment, and organizational health does not mean only an organization that achieves organizational effectiveness in the short term, but rather achieves a set of relatively solid organizational characteristics, this means that a healthy organization is compatible with long-term survival in the environment and creates and expands the capabilities necessary for its survival. There are (11) indicators of organizational health: communication, organizing participation, loyalty, and commitment, credibility or organization reputation, temperament, ethics, job identification or awareness, purpose, leadership, staff competence improvement or development, resources application.

There are also some indicators to assess organizational health including a focus on purpose, good communication, equal authority, use of resources (a manager's ability to use employee talents), organizational attractions factors, employee mood, innovation, and autonomy (employees ability when the manager is absent), compatibility with the environment, and solve the problem ability, and these indicators are still used by companies that are interested in developing organizational health (Jahed, 2015). Therefore, an organization with a healthy organizational climate is an organizational environment that successfully adapts to its environment, as it exploits its resources and efforts to achieve goals, and a healthy organization is one in which the technical, administrative, and institutional levels are in line. Where there is a set of health needs and strategies that the organizations used to meet these needs, including mission needs that are implemented through strategies (focus on goals, appropriate organizational communication, and optimal strength equation) and maintenance needs, implemented through strategies (use of resources, cohesion, and spirit) morality, growth and development) and creativity and innovation needs are implemented through strategies (independence, adaptation, problem-solving competence) (Hoy \& Miksel, 2005).

\subsection{Electronic human resources management (E-HRM) and organizational health}

Many studies have dealt with electronic human resource management, Atallah (2016) indicated that there is an impact of human resource management electronic components in organizational development. Fota and Al-Qutb (2013) concluded that there is an impact of human resource management practices on employees learning and growth in Jordanian banks and in a study conducted by Al-Kasasbeh et al. (2010) which indicated a positive impact of recruitment and selection as one of the human resource management functions dimensions in the learning organization, as their results are also agreed with LópezCabrales et al (2010) who found a relationship between human resource management practices and organizational learning capabilities. Rüel et al. (2014) also indicated that E-HRM use can improve administrative efficiency and reduce costs, therefore the use of this type of management helps to complete the training and development process at the lowest possible costs. Hence, E-HRM's benefits lie in its contribution to improving information dissemination and access, improving opportunities to identify the job, and performance feedback (Stone et al., 2006). Study results of Al-Shakhanbeh (2015) showed a statistically significant impact of human staff in job performance quality, statistically significant impact of human staff, and electronic human resource management software in continuous improvement in Orange Company. Srivastava (2017) study also found that with the implementation of E-HRM, banks are able to carry out their HR activities efficiently. E-HRM decreases human resource costs and reduces administrative workload in most banks, Al-Hmouze (2016) study results showed the positive impact of electronic human resource management on the organization's performance and electronic human resource management in terms of reducing costs and improving procedures to run faster processes and jobs. Ukandu et al (2014) study found that HR employees agreed that E-HRM actually improves efficiency and effectiveness levels in their organizations and that HR managers' use of this system has allowed faster time to transition to higher levels of efficiency, and immediate possibility of feedback on employee inquiries and assist HR managers in making correct decisions. Based on the above study hypothesis can be formulated as follows:

$\mathbf{H}_{1}$ : There is a statistically significant impact of electronic human resources practices on the organizational health of telecommunications companies in Jordan.

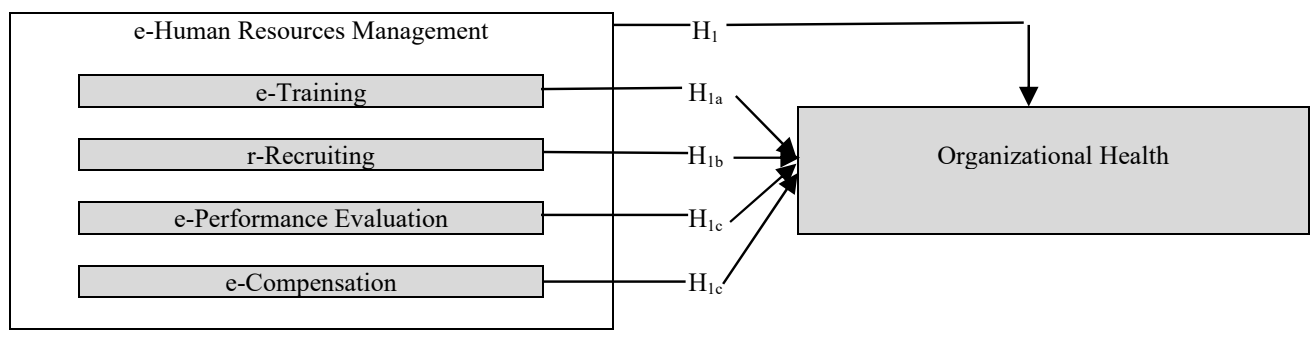

Fig. 1. Research Framework 


\section{Methodology}

\subsection{Population and sample selection}

A qualitative method based on a questionnaire was used in this study for data collection and sample selection. The major aim of the study was to examine the impact of e-HRM on organizational health. Therefore, it focused on telecommunications companies in Jordan. Data were primarily gathered through self-reported questionnaires created in Google Forms and distributed to a purposive sample of senior managers via email. In total, (312) responses were received including (7) invalid to statistical analysis due to uncompleted or inaccurate. Hence, the final sample contained (305) responses suitable to analysis requirements, where it proved to be sufficient to the extent that was predictable and allowed for a presumption of data saturation (Sekaran \& Bougie, 2016).

\subsection{Measurement instrument}

A self-reported questionnaire that consists of two main sections along with a section regarding control variables was used as the measurement instrument. Control variables considered as categorical measures were composed of gender, age group, educational level, and experience. The two main sections were dealt with a five-point Likert scale (from 1= strongly disagree to $5=$ strongly agree). The first section contained (19) items to measure e-HRM based on (Raashidah \& Darakhshan, 2017; Swaroop, 2012). These questions were distributed into dimensions as follows: five items dedicated for measuring e-recruitment, five items dedicated for measuring e-training, four items dedicated for measuring e-performance evaluation, and five items dedicated for measuring e-compensation. Whereas the second section included six items developed to measure organizational health according to what was pointed out by Hoy and Miksel (2005).

\section{Findings}

\subsection{Measurement model evaluation}

This study was conducted structural equation modeling (SEM) to test hypotheses, which represents a contemporary statistical technique for testing and estimating the relationship between factors and variables (Wang \& Rhemtulla, 2021). Accordingly, the reliability and validity of the constructs were tested using confirmatory factor analysis (CFA) through the statistical program AMOSv24. Table 1 summarizes the results of convergent and discriminant validity, as well as the indicators of reliability.

Table 1

Results of validity and reliability tests

\begin{tabular}{|c|c|c|c|c|c|}
\hline Constructs & 1 & 2 & 3 & 4 & 5 \\
\hline 1. E-RE & 0.762 & & & & \\
\hline 2. E-TR & 0.514 & 0.750 & & & \\
\hline 3. E-PE & 0.422 & 0.531 & 0.723 & & \\
\hline 4. $\mathrm{E}-\mathrm{CO}$ & 0.583 & 0.556 & 0.492 & 0.738 & \\
\hline 5. $\mathrm{OHE}$ & 0.669 & 0.685 & 0.673 & 0.690 & 0.755 \\
\hline VIF & 1.925 & 2.568 & 2.084 & 1.854 & --- \\
\hline Loadings range & $0.614-0.839$ & $0.652-0.811$ & $0.673-0.769$ & $0.685-0.805$ & $0.693-0.814$ \\
\hline AVE & 0.581 & 0.563 & 0.523 & 0.544 & 0.570 \\
\hline MSV & 0.513 & 0.457 & 0.508 & 0.482 & 0.516 \\
\hline Internal consistency & 0.872 & 0.862 & 0.811 & 0.851 & 0.885 \\
\hline Composite reliability & 0.873 & 0.865 & 0.814 & 0.856 & 0.888 \\
\hline
\end{tabular}

Note: E-RE: e-recruitment, E-TR: e-training, E-PA: e-performance evaluation, E-CO: e-compensation, OHE: organizational health, Bold fonts refer to square root of average variance extracted.

Table 1 shows that the standard loading values for the individual items were within the domain $(0.614-0.839)$, these values were greater than the minimum retention of the elements based on their standard loads (Al-Lozi et al., 2018; Sung et al., 2019). The average variance extracted (AVE) is a summary indicator of the convergent validity of constructs that must be above 0.50 (Howard, 2018). The results indicate that the AVE values were greater than 0.50 for all constructs, thus the used measurement model has an appropriate convergent validity. Rimkeviciene et al. (2017) suggested the comparison approach as a way to deal with discriminant validity assessment in covariance-based SEM. This approach is based on comparing the values of maximum shared variance (MSV) with the values of AVE, as well as comparing the values of the square root of AVE (VAVE) with the correlation between the rest of the structures. The results show that the values of MSV were smaller than the values of AVE and that the values of $\sqrt{ } \mathrm{AVE}$ were higher than the correlation values among the rest of the constructs. Therefore, the measurement model used is characterized by discriminative validity. The internal consistency measured through Cronbach's Alpha coefficient $(\alpha)$ and compound reliability by McDonald's Omega coefficient $(\omega)$ was conducted as indicators to evaluate the measurement model. The results listed in Table 1 demonstrated that both values of Cronbach's Alpha coefficient and McDonald's Omega coefficient were greater than 0.70 , which is the lowest limit for judging on measurement reliability (De Leeuw et al., 2019). 


\subsection{Structural model}

The structural model illustrated no multicollinearity issue among predictor constructs because variance inflation factor (VIF) values are below the threshold of 5, as shown in Table 1 (Hair et al., 2017). This result is supported by the values of model fit indices shown in Fig. 2.

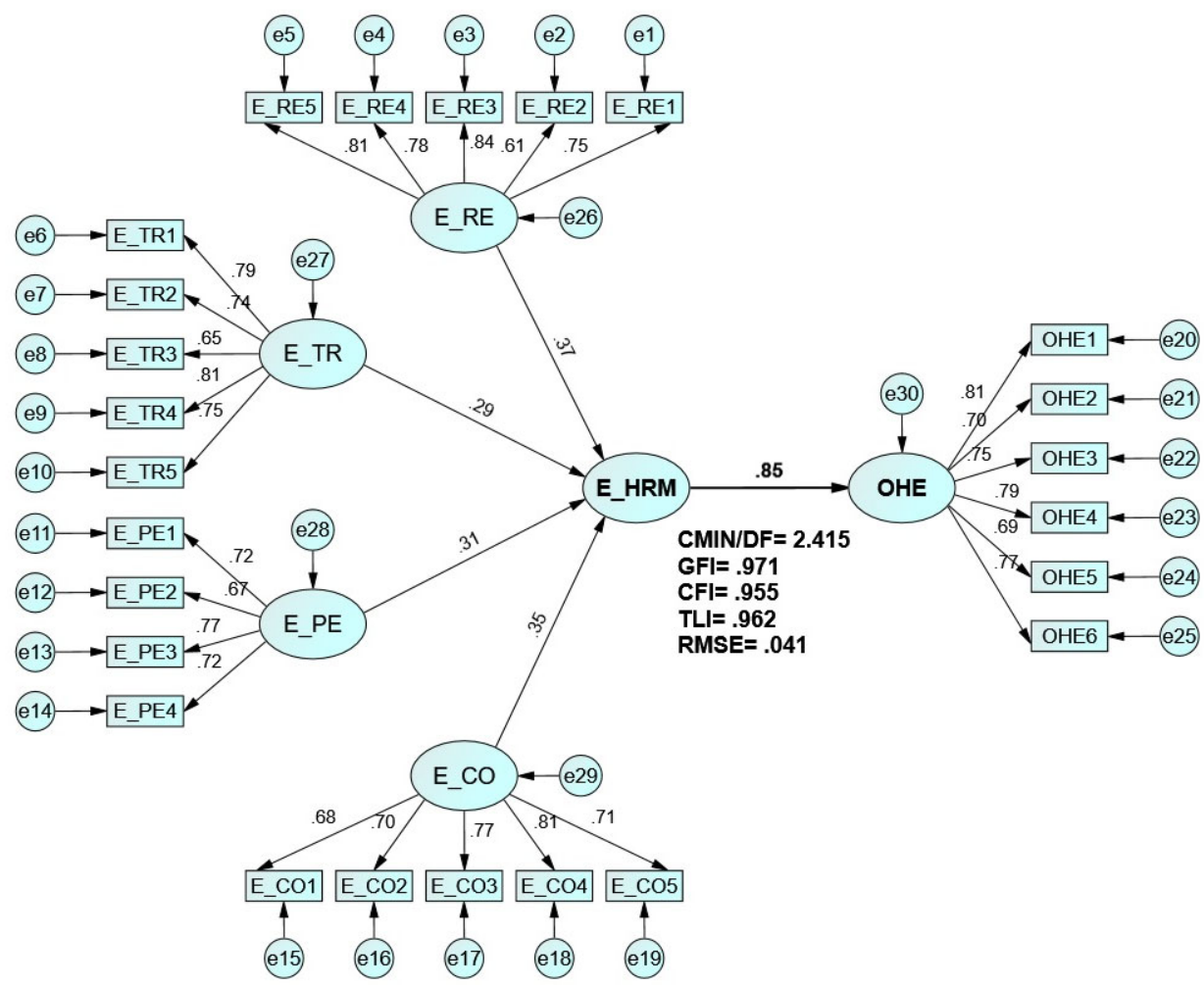

Fig. 2. SEM results of the e-HRM effect on OHE

The results in Fig. 2 indicate that the chi-square to degrees of freedom (CMIN/DF) was 2.415, which is less than 3 the upper limit of this indicator. The values of the goodness of fit index (GFI), the comparative fit index (CFI), and the Tucker-Lewis index (TLI) were higher than the minimum accepted threshold of 0.90 . Moreover, the result of root mean square error of approximation (RMSEA) indicated to value 0.041 , this value is a reasonable error of approximation because it is less than the higher limit of 0.08. Consequently, the structural model used in this study was recognized as a fit model for predicting the DEP and generalization of its result (Ahmad et al., 2016; Shi et al., 2019). To verify the results of testing the study hypotheses, structural equation modeling (SEM) was used, the results of which are listed in Table 2.

Table 2

Hypothesis testing

\begin{tabular}{llcc}
\hline Hypothesis & Relation & Standard Beta & $p$ value \\
\hline H1 & E-HRM $\rightarrow$ OHE & $0.853^{* * *}$ & 39.25 \\
H1a & E-RE $\rightarrow$ OHE & $0.588^{* * *}$ & 25.56 \\
H1b & E-TR $\rightarrow$ OHE & $0.424^{* *}$ & 21.58 \\
H1c & E-PE $\rightarrow$ OHE & $0.487 * *$ & 0.000 \\
H1d & E-CO $\rightarrow$ OHE & $0.397 *$ & 0.002 \\
\hline
\end{tabular}

Note: E-HRM: e-human resource management, E-RE: e-recruitment, E-TR: e-training, E-PA: e-performance evaluation, E-CO: e-compensation, OHE: organizational health, $* p<0.05, * * p<0.01, * * * p<0.001$.

The results demonstrated in Table 2 show that electronic human resource management has a positive impact relationship on organizational health $(\beta=0.853, t=39.25, p=0.000)$, which justifies support for the study's major hypothesis. Moreover, the results indicated that the highest impact was for e-recruitment $(\beta=0.588, t=25.56, p=0.000)$, followed by e-performance evaluation $(\beta=0.487, t=24.82, p=0.004)$, then e-training $(\beta=0.424, t=21.58, p=0.002)$, and finally the lowest impact was for e-compensation $(\beta=0.397, t=19.88, p=0.02)$. Thus, all the minor hypotheses of the study were supported based on these results.

\section{Discussions}

The results indicated that goals clarity levels were average, and this is an indicator that the employee gives priority to goals achievement when completing their tasks. We conclude that the employee has objectives clarity and performs the duties 
through his accurate knowledge of the objectives, and in all the previous cases, these cases generated a perception of the availability of organizations health requirements. It was also found that practicing organizational cohesion levels were medium, the researchers believe that this result indicates that companies, by their work nature and the coordination between all tasks requirements, create organizational coherence, and with passing time the telecommunications companies in Jordan has cohesion culture and this is an indication of the positive relationship between the companies management and employees, and the attractive relations between employees within the telecommunications companies, in a way that achieves interdependence between roles and what constitutes an integrated work unit through which duties are shared with colleagues in a fairly, and this is reinforced by the manager's dealings with subordinates in terms of equality in rights and duties.

With regard to organizational independence level in the telecommunications companies in Jordan, it was also average, as the company's management allows employees to exercise organizational independence by giving them the choice to choose the appropriate method to accomplish their work and giving them the freedom to make decisions related to their business while enjoying independence, this is due to company's work nature, which deals with different behaviors of customers, which requires employees be independence in dealing behavior to take some decisions to save the customer's time. In addition, independence gives employees their own choice in solving the problems they face without referring to their supervisors.

The results showed that the E-HRM practices adoption level in telecommunications companies in Jordan was medium. This result indicates companies' management direction towards integrating technology with organizations functions by investing in information and communication technologies, especially in the human resources field, because of this management importance, to achieve efficiency and reduce costs, especially in light of globalization and international competitors' entry. EHRM system also speeds up transactions arrival, reduces errors related to information, improves tracking and control of human resources procedures, and improves human resources management strategic direction, which is reflected in improving customer service, especially as we are talking about an important sector, which is telecommunications sector, which requires searching for all ways to improve service provision level and trying to control costs.

Study results showed an impact of electronic human resources practices on organizational health in telecommunications companies in Jordan. And this explains that E-HRM adoption enabled companies to attract qualified individuals from multiple geographical areas that contributed to workforce diversity and new organizational culture creation with diverse knowledge and skills that possess creative ideas, through teamwork, information exchange, and knowledge dissemination, and this contributed to achieving the company's learning capabilities that can formulate accurate goals and also a follow-up of goals achievement. In addition, training gives the employee the required skills, especially if it is followed up and the worker's needs are determined by scientific methods based on electronic tools use, which enables the employees to increase their abilities to make individual decisions in accomplishing tasks using the accumulated experience they have. Rüel et al. (2004) found that E-HRM use can improve efficiency and reduce costs, and therefore the use of this type of management helps to complete the process of training and development at the lowest possible costs. On the other hand, results showed that electronic performance appraisal and electronic compensation have an impact on organizational health, as they allow employees to get rid of negative causes such as bias in performance appraisal in addition to encouraging employees through incentives and building communication channels between employees and management and the workers themselves. Hence, E-HRM's benefit lies in that it contributes to improving information dissemination and access, improving the ability to identify job opportunities, performance feedback (Stone et al., 2006), and achieving organizational cohesion.

\section{Recommendations}

Based on study results, the researchers recommend managers and decision-makers to invest in electronic human resources systems, which allow the company to fully implement human resources practices electronically, to obtain economic savings and be able to attract talents, and to focus more on the electronic training and development process in order to raise individual's practical capabilities, which is reflected on their creativity by encouraging workers to attend electronic workshops and conferences, attend electronic meetings, open dialogue and benefit from the successful experiences of competitors in the same sector. Activating electronic recruitment process and intensifying electronic advertisements to attract competencies and talents all over the world to enhance creative capabilities and excellence, also encouraging communication between employees and managers, opening dialogue and discussion, working to reduce organizational structure hierarchy, and encouraging work teams. Finally Granting employees greater authority equal with their job position, skills, and expertise, and allowing them to express their opinion and take the other opinion.

\section{References}

Alameeri, K., Alshurideh, M., Al Kurdi, B., \& Salloum, S. A. (2020, October). The effect of work environment happiness on employee leadership. In International Conference on Advanced Intelligent Systems and Informatics (pp. 668-680). Springer, Cham.

Aburayya, A., Alshurideh, M., Alawadhi, D., Alfarsi, A., Taryam, M., \& Mubarak, S. (2020). An investigation of the effect of lean six sigma practices on healthcare service quality and patient satisfaction: testing the mediating role of service quality in Dubai primary healthcare sector. Journal of Advanced Research in Dynamical and Control Systems, 12(8), 5672. 
Ahmad, A., Alshurideh, M., Al Kurdi, B., Aburayya, A., \& Hamadneh, S. (2021). Digital transformation metrics: a conceptual view. Journal of management Information and Decision Sciences, 24(7), 1-18.

Ahmad, A., Alshurideh, M. T., Al Kurdi, B. H., \& Salloum, S. A. (2021). Factors Impacts Organization Digital Transformation and Organization Decision Making During Covid19 Pandemic. The Effect of Coronavirus Disease (COVID-19) on Business Intelligence, 334, 95.

Ahmad, S., Zulkurnain, N., \&Khairushalimi, F. (2016). Assessing the Validity and Reliability of a Measurement Model in Structural Equation Modeling (SEM). British Journal of Mathematics \& Computer Science, 15(3), 1-8. https://doi.org/10.9734/BJMCS/2016/25183

Al-Dhuhouri, F. S., Alshurideh, M., Al Kurdi, B., \& Salloum, S. A. (2020, October). Enhancing our understanding of the relationship between leadership, team characteristics, emotional intelligence and their effect on team performance: A Critical Review. In International Conference on Advanced Intelligent Systems and Informatics (pp. 644-655). Springer, Cham.

Al Hamad, A. Q. (2016, February). Students' perception of implementing a Smart Learning System (SLS) based on Moodle at Fujairah College. In 2016 13th International Conference on Remote Engineering and Virtual Instrumentation (REV) (pp. 315-318). IEEE.

AlHamad, A. Q. M. (2020). Acceptance of E-learning among university students in UAE: A practical study. International Journal of Electrical \& Computer Engineering (2088-8708), 10(4), 3660-3671.

AlHamad, A. Q. M., \& AlHammadi, R. A. (2018, March). Students' perception of E-library system at Fujairah University. In International Conference on Remote Engineering and Virtual Instrumentation (pp. 659-670). Springer, Cham.

AlHamad, A. Q., Al Omari, F., \& AlHamad, A. Q. (2014). Recommendation for Managing Patients' Privacy in an Integrated Health Information Network. Journal of Information Technology \& Economic Development, 5(1), 47-52.

AlHamad, A. Q., \& Al Qawasmi, K. I. (2014). Building an ethical framework for e-learning management system at a university level. Journal of Engineering and Economic Development, 1(1), 11-16.

AlHamad, A. Q., Yaacob, N., \& Al-Omari, F. (2012, September). Applying JESS rules to personalize Learning Management System (LMS) using online quizzes. In 2012 15th International Conference on Interactive Collaborative Learning (ICL) (pp. 1-4). IEEE.

AlHamad, M., Akour, I., Alshurideh, M., Al-Hamad, A., Kurdi, B., \& Alzoubi, H. (2021). Predicting the intention to use google glass: A comparative approach using machine learning models and PLS-SEM. International Journal of Data and Network Science, 5(3), 311-320.

Al-Hamad, M., Mbaidin, H., AlHamad, A., Alshurideh, M., Kurdi, B., \& Al-Hamad, N. (2021). Investigating students' behavioral intention to use mobile learning in higher education in UAE during Coronavirus-19 pandemic. International Journal of Data and Network Science, 5(3), 321-330.

Al-Hawajreh, K., AL-Zeaud, H.., Al-Hawary, S. I.., \& Mohammad, A. A. (2011). The Influence of Top Management Support and Commitment on Total Quality Management Indicators from Managers and Heads of Departments Viewpoint: A Case Study of Sahab Industrial City. Jordan Journal of Business Administration, 7(4), 557-576.

Alkalha, Z., Al-Zu'bi, Z., Al-Dmour, H., Alshurideh, M., \& Masa'deh, R. (2012). Investigating the effects of human resource policies on organizational performance: An empirical study on commercial banks operating in Jordan. European Journal of Economics, Finance and Administrative Sciences, 51(1), 44-64.

Al Kurdi, B., Elrehail, H., Alzoubi, H., Alshurideh, M., \& Al-Adaila, R. (2021). The interplay among HRM practices, job satisfaction and intention to leave: An empirical investigation. Journal of Legal, Ethical and Regulatory, 24(1), 1-14.

Al Kurdi, B., Alshurideh, M., \& Salloum, S. A. (2020). Investigating a theoretical framework for e-learning technology acceptance. International Journal of Electrical and Computer Engineering (IJECE), 10(6), 6484-6496.

Al-Maroof, R., Ayoubi, K., Alhumaid, K., Aburayya, A., Alshurideh, M., Alfaisal, R., \& Salloum, S. (2021). The acceptance of social media video for knowledge acquisition, sharing and application: A comparative study among YouYube users and TikTok users' for medical purposes. International Journal of Data and Network Science, 5(3), 197-214.

Al-Lozi, M.., Almomani, R. Z.., \& Al-Hawary, S. I. (2018). Talent Management strategies as a critical success factor for effectiveness of Human Resources Information Systems in commercial banks working in Jordan. Global Journal of Management and Business Research: A Administration and Management, 18(1), 30-43.

Allozi, A., Alshurideh, M., AlHamad, A., \& Al Kurdi, B. (2022). Impact of transformational leadership on the job satisfaction with the moderating role of organizational commitment: case of UAE and Jordan manufacturing companies. Academy of Strategic Management Journal, 21(Special Issue 2), 1-13.

Al-Mashaqbeh, I. F., \& Al Hamad, A. (2010, May). Student's perception of an online exam within the decision support system course at Al al Bayt University. In 2010 Second International Conference on Computer Research and Development (pp. 131-135). IEEE.

AlMehrzi, A., Alshurideh, M., \& Al Kurdi, B. (2020). Investigation of the key internal factors influencing knowledge management, employment, and organisational performance: a qualitative study of the UAE hospitality sector. International Journal of Innovation, Creativity and Change, 14(1), 1369-1394.

Al Mehrez, A. A., Alshurideh, M., Al Kurdi, B., \& Salloum, S. A. (2020, October). Internal factors affect knowledge management and firm performance: a systematic review. In International Conference on Advanced Intelligent Systems and Informatics (pp. 632-643). Springer, Cham.

Alomari, K. M., AlHamad, A. Q., Salloum, S., \& Salloum, S. A. (2019). Prediction of the digital game rating systems based on the ESRB. Opcion, 35(19), 1368-1393.

AlShehhi, H., Alshurideh, M., Al Kurdi, B., \& Salloum, S. A. (2020, October). The impact of ethical leadership on employees 
performance: A systematic review. In International Conference on Advanced Intelligent Systems and Informatics (pp. 417-426). Springer, Cham.

Alshraideh, A. T. R., Al-Lozi, M., \& Alshurideh, M. T. (2017). The impact of training strategy on organizational loyalty via the mediating variables of organizational satisfaction and organizational performance: An empirical study on Jordanian agricultural credit corporation staff. Journal of Social Sciences (COES\&RJ-JSS), 6(2), 383-394.

Alshurideh, M., Al Kurdi, B., \& Salloum, S. A. (2019, October). Examining the main mobile learning system drivers' effects: A mix empirical examination of both the Expectation-Confirmation Model (ECM) and the Technology Acceptance Model (TAM). In International Conference on Advanced Intelligent Systems and Informatics (pp. 406-417). Springer, Cham.

Alshurideh, M., Al Kurdi, B., Salloum, S. A., Arpaci, I., \& Al-Emran, M. (2020). Predicting the actual use of m-learning systems: a comparative approach using PLS-SEM and machine learning algorithms. Interactive Learning Environments, $1-15$.

Alshurideh, M., Salloum, S. A., Al Kurdi, B., Monem, A. A., \& Shaalan, K. (2019). Understanding the quality determinants that influence the intention to use the mobile learning platforms: A practical study. International Journal of Interactive Mobile Technologies, 13(11), 183-157.

Alshurideh, M., Kurdi, B. A., Shaltoni, A. M., \& Ghuff, S. S. (2019). Determinants of pro-environmental behaviour in the context of emerging economies. International Journal of Sustainable Society, 11(4), 257-277.

Alshurideh, M. T., Al Kurdi, B., \& Salloum, S. A. (2021). The moderation effect of gender on accepting electronic payment technology: a study on United Arab Emirates consumers. Review of International Business and Strategy, 31(3), $375-396$.

Alshurideh, M., Al Kurdi, B. H., Vij, A., Obiedat, Z., \& Naser, A. (2016). Marketing ethics and relationship marketing-An empirical study that measure the effect of ethics practices application on maintaining relationships with customers. International Business Research, 9(9), 78-90.

Atallah, Asmaa Ata (2016). The Impact of Electronic Human Resource Management (E-HRM) on Organizational Development of UNRWA in Gaza Strip,the Islamic University Gaza.

Asfahani, A. M. (2021). The Complementary Relationship between Human Resources Accounting and Human Resources Information System. Open Journal of Accounting, 10(02), 30-41.

Alzoubi, H. M., Alshurideh, M., \& Ghazal, T. M. (2021, June). Integrating BLE Beacon Technology with Intelligent Information Systems IIS for Operations' Performance: A Managerial Perspective. In The International Conference on Artificial Intelligence and Computer Vision (pp. 527-538). Springer, Cham.

Bondarouk, T., Ruël, H., \& van der Heijden, B. (2009). E-HRM effectiveness in a public sector organization: a multi-stakeholder perspective. The International Journal of Human Resource Management, 20(3), 578-590.

Bottiani, H., Bradshaw, C. P., \& Mendelson, T. (2014). Promoting an equitable and supportive school climate in high schools: The role of school organizational health and staff burnout. Journal of School Psychology, 52, 567-582.

Candy, R. L. \& Miller, J. S. (2003), Technology: Implications for HRM. In D. Stone (Ed), Advances in human performance and cognitive engineering research. (pp. 99-118), Greenwich, CT, JAI Press.

De Leeuw, E., Hox, J., Silber, H., Struminskaya, B., \& Vis, C. (2019). Development of an international survey attitude scale: Measurement equivalence, reliability, and predictive validity. Measurement Instruments for the Social Sciences, 1(1), 9. https://doi.org/10.1186/s42409-019-0012-x

Dhamija, P. (2012). E-Recruitment: A Roadmap Towards E-Human Resource Management. International Refereed Research Journal, 3(2), 33-39.

Elshamy, A. M., Abdelghany, M. A., Alhamad, A. Q., Hamed, H. F., Kelash, H. M., \& Hussein, A. I. (2017, September). Secure implementation for video streams based on fully and permutation encryption techniques. In 2017 International Conference on Computer and Applications (ICCA) (pp. 50-55). IEEE.

Ghazal, T. M., Hasan, M. K., Alshurideh, M. T., Alzoubi, H. M., Ahmad, M., Akbar, S. S., ... \& Akour, I. A. (2021). IoT for Smart Cities: Machine learning approaches in smart healthcare-a review. Future Internet, 13(8), 1-19.

Gueutal, H. G., \& Stone, (Eds.) (2005). The brave new world of eHR: Human resources management in the digital age. San Francisco, CA: Jossey-Bass.

Hair, J. F., Babin, B. J., \&Krey, N. (2017). Covariance-Based Structural Equation Modeling in the Journal of Advertising: Review and Recommendations. Journal of Advertising, 46(1), 163-177. https://doi.org/10.1080/00913367.2017.1281777

Hansson, S. (2008). Determinants of Individual and Organizational Health in Human Service Professions. Acta Universtis Upsaliesis Uppsala. Digital Comprehensive Summaries of Uppsala Dissertations from the Faculty of Medicine 348.

Howard, M. C. (2018). The convergent validity and nomological net of two methods to measure retroactive influences. Psychology of Consciousness: Theory, Research, and Practice, 5(3), 324-337. https://doi.org/10.1037/cns0000149

Hoy, W. \& Miksel, C. (2005). Educational administration: Theory, research and practice, (7 $7^{\text {th }}$ ed.), New York, NY: McGrawHill.

Jahed, H. (2015). Organizational health. TADBIR J., 159(16), 16-21.

Korkmaz, M. (2007). Orgutselsaglikuzerindeliderlikstillerininetkisi. Kuram and Uygulamada Egitim Yonetimi Dergisi, 13(1), 57-91.

Kurdi, B., \& Alshurideh, M., \& Al afaishata (2020b). Employee retention and organizational performance: Evidence from banking industry. Management Science Letters, 10(16), 3981-3990.

Kurdi, B., Alshurideh, M., \& Alnaser, A. (2020a). The impact of employee satisfaction on customer satisfaction: Theoretical and empirical underpinning. Management Science Letters, 10(15), 3561-3570. 
Miles, B. (1969). Planned change and organizational health: figure and ground. In. F.D Carver \& T.J Sergiovanni (Eds.). Organizations and human behavior, 375-391.

Mousavidavoudi, S.M. \&Fartash, K. (2012), Electronic Human Resource Management: New Avenues which Leads to Organizational Success. Pinnacle Research Journals, 1(2), May, 75-87.

Odeh, R. B. M., Obeidat, B. Y., Jaradat, M. O., \& Alshurideh, M. T. (2021). The transformational leadership role in achieving organizational resilience through adaptive cultures: the case of Dubai service sector. International Journal of Productivity and Performance Management. Vol. ahead-of-print No. ahead-of-print. https://doi.org/10.1108/IJPPM-02-2021-0093

Otair, M. A., \& Hamad, A. Q. A. (2005). Expert personalized e-learning recommender system. Retrieved June, 13, 2010.

Parker, O. \&Whright, L. (2001). Pay and employee commitment: the missing link. Ivey Business Journal, 65(i3), 70-79.

Piggot-Irvine, E. (2003). Key features of appraisal effectiveness. The International Journal of Educational Management, 17(6), 254-261.

Raashidah, G., Darakhshan, A. (2017). E- Human Resource Management (e-HRM). International Journal of Emerging Research in Management \& Technology, 6(6), 2278-9359.

Yusliza, M. Y., \& Ramayah, T. (2011). Explaining the intention to use electronic HRM among HR professionals: results from a pilot study. Australian Journal of Basic and Applied Sciences, 5(8), 489-497.

Ramayah, T., Ahmad, N.H, Hong, T.S. (2012). An Assessment of E-Training Effectiveness in Multinational Companies in Malaysia. Educational Technology \& Society, 15(2), 125-137.

Rimkeviciene, J., Hawgood, J., O’Gorman, J., \& De Leo, D. (2017). Construct Validity of the Acquired Capability for Suicide Scale: Factor Structure, Convergent and Discriminant Validity. Journal of Psychopathology and Behavioral Assessment, 39(2), 291-302. https://doi.org/10.1007/s10862-016-9576-4

Sekaran, U., \& Bougie, R. (2016). Research methods for business: A skill-building approach (Seventh edition). Wiley.

Shamout, M., Elayan, M., Rawashdeh, A., Kurdi, B., \& Alshurideh, M. (2022). E-HRM practices and sustainable competitive advantage from HR practitioner's perspective: A mediated moderation analysis. International Journal of Data and Network Science, 6(1), 165-178.

Shi, D., Lee, T., \&Maydeu-Olivares, A. (2019). Understanding the Model Size Effect on SEM Fit Indices. Educational and Psychological Measurement, 79(2), 310-334. https://doi.org/10.1177/0013164418783530

Stone, D.L., Stone-Romero, E.F., Lukaszewski, K. (2006), Factors Affecting The Acceptance and Effectiveness of Electronic Human Resource Systems. Human Resource Management Review, 16, 229-244.

Strohmeier, S. (2007). Research in E-HRM: Review and implications. Human Resource Management Review, $17,19-37$.

Sung, K.-S., Yi, Y. G., \& Shin, H.-I. (2019). Reliability and validity of knee extensor strength measurements using a portable dynamometer anchoring system in a supine position. BMC Musculoskeletal Disorders, 20(1), 1-8. https://doi.org/10.1186/s12891-019-2703-0

Swaroop, K. R. (2012). E-HRM and how it will reduce the Cost in Organization. Asia Pacific Journal of Marketing \& Management Review, 1(4), 133-139.

Vansant, O. (2000). Organizational health, health ventures in publication. Columbia university, U.S.A.

Voermansm, M., \& Van Veldhoven, M. (2007). Attitude towards e-HRM: An Empirical Study at Philips. Personnel Review, 36(6), 887-902.

Wang, Y. A., \&Rhemtulla, M. (2021). Power Analysis for Parameter Estimation in Structural Equation Modeling: A Discussion and Tutorial. Advances in Methods and Practices in Psychological Science, 4(1), 1-17. https://doi.org/10.1177/2515245920918253

Xenidis, Y. \&Theorcharous, K. (2014). Organizational health: definition and assessment. Procedia Engineering, 85, $562-570$.

Yuliawati, N. M., Icih, I., \& Kurniawan, A. (2021). The effect of E-Procurement system implementation, competence and compensation on employee performance of goods/services procurement. ACCRUALS (Accounting Research Journal of Sutaatmadja), 5(01), 103-111.

Zafar, J. (2010). The role of information technology in the personnel department: HRM in the knowledge economy. Canadian Social Science, 6(5), 54-59.

Zu'bi, Z., Al-Lozi, M., Dahiyat, S., Alshurideh, M., \& Al Majali, A. (2012). Examining the effects of quality management practices on product variety. European Journal of Economics, Finance and Administrative Sciences, 51(1), $123-139$.

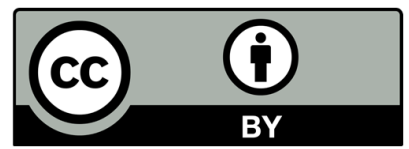

(C) 2022 by the authors; licensee Growing Science, Canada. This is an open access article distributed under the terms and conditions of the Creative Commons Attribution (CC-BY). license (http://creativecommons.org/licenses/by/4.0/). 